\title{
Vapor-liquid equilibria of carbon dioxide with isopropyl acetate, diethyl carbonate and ethyl butyrate at elevated pressures
}

\author{
Chen-His Cheng, Yan-Ping Chen* \\ Department of Chemical Engineering, National Taiwan University, Taipei 106, Taiwan, ROC
}

Received 1 March 2005; received in revised form 22 May 2005; accepted 26 May 2005

Available online 11 July 2005

\begin{abstract}
Vapor-liquid equilibria for carbon dioxide with three esters of isopropyl acetate, diethyl carbonate and ethyl butyrate were measured in this study at $308.45,313.45$ and $318.55 \mathrm{~K}$ and at elevated pressures up to $8.9 \mathrm{MPa}$. A static type phase equilibrium apparatus with visual sapphire windows was used in the experimental measurements. Equilibrium compositions in both vapor and liquid phases and the vapor-liquid equilibrium (VLE) constants are reported. The solubility for each ester compound in the vapor phase is in the order of $10^{-3}$ mole fraction. These new VLE data were correlated using either the equation of state (EOS) or activity coefficient model. It is shown that the Peng-Robinson or Soave-Redlich-Kwong EOS with van der Waals mixing rules gives satisfactory results. These VLE data are also well correlated by the UNIQUAC activity coefficient model with two optimally fitted binary interaction parameters.
\end{abstract}

(C) 2005 Elsevier B.V. All rights reserved.

Keywords: Vapor-liquid equilibrium; High pressure; Binary mixtures

\section{Introduction}

Vapor-liquid equilibrium (VLE) data at high pressures are important for chemical process such as supercritical extraction. Carbon dioxide is the most commonly used supercritical fluid. Although many phase equilibrium data have been presented in literature [1-3], VLE or gas solubility for carbon dioxide with ester compounds is still inadequate. In our previous studies [4-6], we have measured the VLE data for carbon dioxide with several ester compounds using a semi-flow apparatus up to $13 \mathrm{MPa}$. In this study, we measured the VLE data for three binary mixtures for carbon dioxide with isopropyl acetate, diethyl carbonate and ethyl butyrate using a static apparatus with visual sapphire windows. Isopropyl acetate and ethyl butyrate are used as perfume or aroma additives for cosmetics and food industries. Diethyl carbonate is used in organic synthesis or the production of resin. The experimental temperatures are at $308.45,313.45$ and $318.55 \mathrm{~K}$, with pressure range from 3 to $8.9 \mathrm{MPa}$. To our knowledge, the

\footnotetext{
* Corresponding author. Fax: +88622362 3040.

E-mail address: ypchen@ntu.edu.tw (Y.-P. Chen).
}

VLE data for these systems at the above conditions are not available in literature. This study presents new phase equilibrium data at elevated pressures. The measured data were also correlated using either the equation of state (EOS) with empirical mixing rules, or the commonly used activity coefficient model.

\section{Experimental}

\subsection{Chemicals}

Liquefied carbon dioxide at high pressure with purity greater than 99.9 mass\% was purchased from San-Fu Chemical Co. (Taiwan). Isopropyl acetate, diethyl carbonate and ethyl butyrate were purchased from Acros. The properties for pure ester compounds were measured in this study and the results are shown in Table 1. The refractive indices were measured at $293.15 \mathrm{~K}$ using an Abbe refractometer, Atago 3 , with an accuracy of \pm 0.0001 . The densities of pure compounds were measured at 293.15 or $298.15 \mathrm{~K}$ using the Anton Paar DMA 58 density meter with an accuracy of 
Table 1

Comparison of the measured refractive indices and densities of pure solvents with literature data

\begin{tabular}{|c|c|c|c|c|c|}
\hline \multirow[t]{2}{*}{ Component } & \multicolumn{2}{|c|}{ Refractive index (293.15 K) } & \multicolumn{2}{|c|}{ Density $\left(\mathrm{kg} \mathrm{m}^{-3}\right)$} & \multirow[t]{2}{*}{ GC purity (mass $\%$ ) } \\
\hline & Experiment & Literature [18] & Experiment & Literature & \\
\hline Ethanol & 1.3592 & 1.3594 & $789.4^{\mathrm{a}}$ & $789.4[17]$ & $>99.9$ \\
\hline Isopropyl acetate & 1.3751 & 1.3750 & $866.4^{\mathrm{b}}$ & $870.2[19]$ & $>99.5$ \\
\hline Diethyl carbonate & 1.3830 & 1.3829 & $969.2^{\mathrm{b}}$ & $969.3[19]$ & $>99.6$ \\
\hline Ethyl butyrate & 1.3899 & 1.3900 & $879.0^{\mathrm{a}}$ & $878.9[17]$ & $>99.3$ \\
\hline
\end{tabular}

a $T=293.15 \mathrm{~K}$.

b $T=298.15 \mathrm{~K}$.

$\pm 0.1 \mathrm{~kg} \mathrm{~m}^{-3}$. The measured refractive index and densities agree well with literature data. The purities of all chemicals are greater than 99 mass \% that were measured using gas chromatograph (GC). These chemicals were used without further purification.

\subsection{Apparatus}

The phase equilibrium apparatus of this study is shown in Fig. 1. It is a static type apparatus with circulation of the liquid phase. There are mainly three sections for the input of sample, the high-pressure equilibrium cell and the analysis for compositions of the equilibrium phases. The equilibrium cell was made by stainless steel with an internal volume of $320 \mathrm{~mL}$. There are six visual sapphire windows (Sitec, Switzerland) in the equilibrium cell for the visual observation of the phase behavior. The pressure in the equilibrium cell was measured by a Druck pressure gauge (PDCR-4031) with a digital indicator (DPI-281). The range of the pressure gauge is up to 700 bar, with a resolution of \pm 0.35 bar and an estimated accuracy of $\pm 0.05 \%$ of the digital reading value. The temperature in the equilibrium cell was measured by a K-type thermocouple. The digital indicator has a resolution of $0.01 \mathrm{~K}$ and an estimated accuracy of $\pm 0.1 \mathrm{~K}$. The liquid phase was recir- culated to reach the equilibrium condition using a duplex metering pump (LCD, Analytical Inc.). Equilibrium samples were taken by the sampling valves. The vapor sampling valve (Valco, 6UW) has an external loop with volume of $20 \mu \mathrm{L}$. The liquid sampling valve (Rheodyne, 7010) has an external loop with volume of $5 \mu \mathrm{L}$. On-line analyses for the equilibrium compositions have been carried out using GC (Shimadzu 14B). The GC was equipped with a thermal conductivity detector (TCD) and a column $2 \mathrm{~m}$ in length with 1/8 in. diameter packed with Porapak P. The equilibrium cell and the sampling valves were all immersed in a water bath controlled by a PID controller. The estimated accuracy for measured temperature is $\pm 0.1 \mathrm{~K}$. Heating tapes were used for lines between the bath and GC to keep the temperature at $\pm 0.1 \mathrm{~K}$ of a desired value through a PID controller. Helium was used as the carrier gas with a flow rate of $45 \mathrm{~mL} \mathrm{~min}^{-1}$. The TCD detector was kept at $483.15 \mathrm{~K}$. The column of the GC was kept at $373.15 \mathrm{~K}$ for $\mathrm{CO}_{2}+$ isopropyl acetate, and at $413.15 \mathrm{~K}$ for the other two systems. The current of TCD was $70 \mathrm{~mA}$.

\subsection{Calibration procedures}

The volumes of the sampling loops were calibrated using the similar procedures in literature $[7,8]$. These loops were



Fig. 1. Schematic diagram of the high-pressure experimental apparatus used in this study. (1) $\mathrm{CO}_{2}$ cylinder, (2) cooler, (3) liquid pump, (4) water bath, (5) high-pressure vessel, (6) circulation pump, (7) sapphire window unit, (8) needle valve, (9) check valve, (10) two-way valve, (11) ball valve, (12) GC, (13) vacuum pump, (14) He cylinder, (15) degas/feeding unit, (16) gas sampling valve, (17) liquid sampling valve, (18) drain bottle, (19) thermocouple, (20) pressure transmitter and (21) analysis unit. 
calibrated using distilled water controlled at $298.15 \mathrm{~K}$. With the measured weights of the sampling loops and the known density of water at the given temperature, the loop volumes were determined as 21.83 and $4.52 \mu \mathrm{L}$ for the vapor and liquid sampling loops, respectively.

The on-line GC method was used to analyze the equilibrium compositions. The calibration of GC was made by plotting the peak areas against the number of moles of the pure gas or liquid sample, as was presented by previous investigators $[9,10]$. For the liquid samples, the weighting method on a digital balance (Mettler Toledo AX105, $\pm 2 \times 10^{-5} \mathrm{~g}$ ) was used to evaluate the weight and number of moles. The GC peak areas for three ester compounds were plotted against their number of moles, respectively. The third-order polynomial curve fitting was found satisfactory for these pure liquid sample calibration curves. Calibrations for the gas samples were performed when carbon dioxide was pressurized to a desired value in an isothermal water bath. With the gas sampling valves connected to GC, the peak areas were obtained at various $T$ and $P$ conditions. The molar volumes for carbon dioxide at various $T$ and $P$ conditions were calculated using the data base of NIST [11]. From the molar volumes of carbon dioxide and the loop volumes of the gas sampling valve, numbers of moles of carbon dioxide were determined in the calibrations. Third-order polynomial curves were also observed for gas phase calibration at each isotherm.

\subsection{Experimental procedures}

The experimental apparatus was evacuated to a subatmospheric pressure and the $\mathrm{CO}_{2}+$ ester compounds were injected through the system for cleaning before each VLE measurement. The liquid ester solvent was degassed for $20 \mathrm{~min}$ before charging into the equilibrium cell immersed in a water bath. The $\mathrm{CO}_{2}$ was then fed into the system through the high-pressure pump to a desired pressure. The liquid phase sample was recirculated through a metering pump at a flow rate of $9 \mathrm{~mL} \mathrm{~min}^{-1}$ in order to enhance rapid equilibrium. At all experimental conditions, equilibrium vapor and liquid phases were visually observed after $12 \mathrm{~h}$ of recirculation through the windows of the equilibrium cell. The system was then settled for $3.5 \mathrm{~h}$ to reach the final equilibrium. The final pressure reading was recorded and the equilibrium compositions of the two phases were analyzed by GC. During the liquid sampling procedures, the flow rate of the metering pump was carefully controlled to minimize the disturbance of the equilibrium state. The equilibrium compositions were the averaged values of more than five repeated measurements. The sampling loops were then evacuated to remove any residual. The accuracy of the equilibrium compositions was estimated as \pm 0.002 mole fraction in this study.

\section{Results and discussion}

The VLE measurements for the binary mixture of $\mathrm{CO}_{2}+$ ethanol were first carried out and compared with liter-

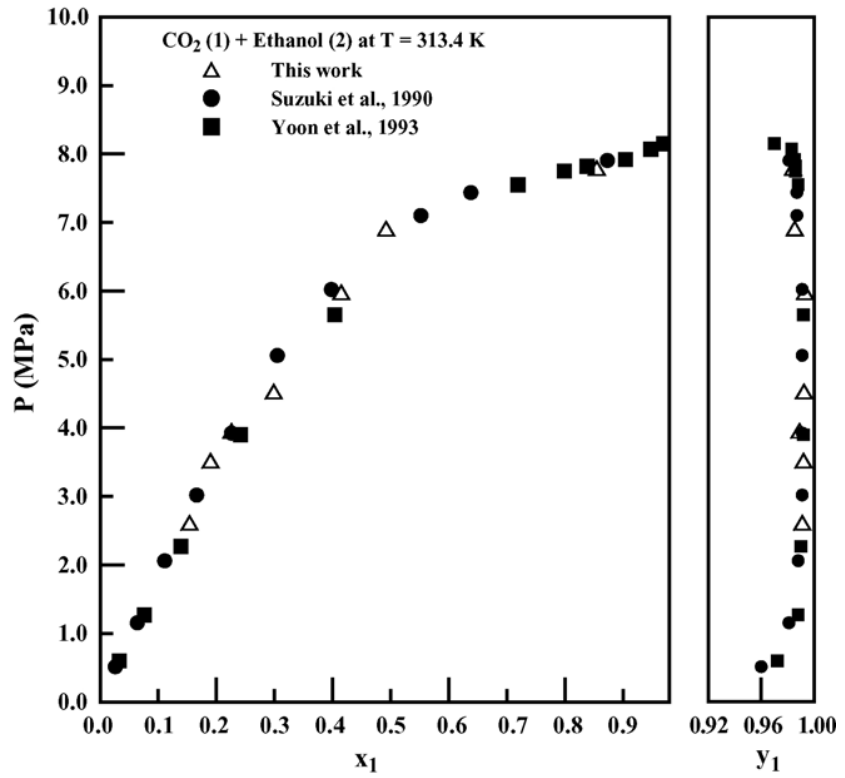

Fig. 2. Comparison of the $P-x-y$ data for the binary mixture of $\mathrm{CO}_{2}$ (1) + ethanol (2) at $313.4 \mathrm{~K}$.

ature data [7,9]. The result is presented graphically in Fig. 2 . The measured data in this study agree well with those in previous literature and the reliability of the apparatus in this study is confirmed. The measured equilibrium compositions and the corresponding $K_{1}$ values $\left(K_{1}=y_{1} / x_{1}\right)$ at various temperature and pressure states for three binary mixtures are shown in Tables 2-4, respectively. The standard deviations for the equilibrium liquid and vapor compositions from repeated measurements are less than $10^{-3}$ and $10^{-4}$ mole fractions, respectively. Graphical representations of the VLE results are shown in Figs. 3-5, respectively. Generally, the solubility of $\mathrm{CO}_{2}$ in the liquid phase increases with pressure but decreases with temperature. The vapor phase contains mainly $\mathrm{CO}_{2}$ of more than $99 \mathrm{~mol} \%$.

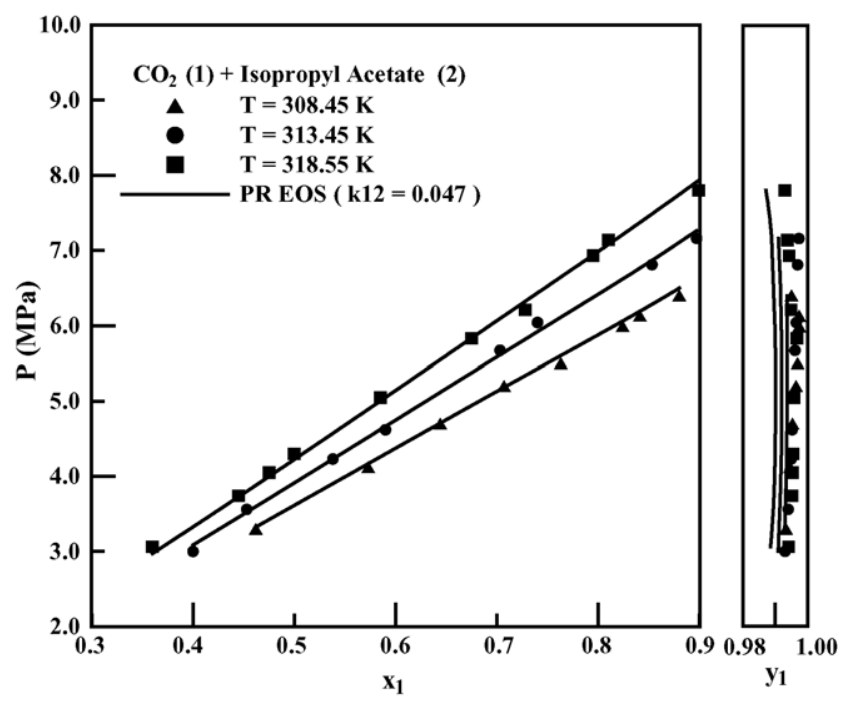

Fig. 3. VLE results of the binary mixture of $\mathrm{CO}_{2}(1)+$ isopropyl acetate (2). 
Table 2

Experimental VLE results for the binary mixture of $\mathrm{CO}_{2}(1)+$ isopropyl acetate (2)

\begin{tabular}{|c|c|c|c|}
\hline \multirow[t]{2}{*}{ Pressure (MPa) } & \multicolumn{2}{|c|}{ Equilibrium composition } & \multirow{2}{*}{$\begin{array}{l}\text { Equilibrium } \\
\text { constant, } K_{1}\end{array}$} \\
\hline & $x_{1}$ & $y_{1}$ & \\
\hline \multicolumn{4}{|l|}{$T=308.45 \mathrm{~K}$} \\
\hline 3.30 & 0.462 & 0.9933 & 2.150 \\
\hline 4.12 & 0.573 & 0.9946 & 1.736 \\
\hline 4.70 & 0.644 & 0.9953 & 1.545 \\
\hline 5.20 & 0.707 & 0.9964 & 1.409 \\
\hline 5.50 & 0.763 & 0.9969 & 1.307 \\
\hline 5.99 & 0.824 & 0.9974 & 1.210 \\
\hline 6.13 & 0.841 & 0.9974 & 1.186 \\
\hline 6.40 & 0.880 & 0.9950 & 1.131 \\
\hline \multicolumn{4}{|l|}{$T=313.45 \mathrm{~K}$} \\
\hline 3.08 & 0.400 & 0.9930 & 2.483 \\
\hline 3.56 & 0.453 & 0.9940 & 2.194 \\
\hline 4.23 & 0.538 & 0.9949 & 1.849 \\
\hline 4.62 & 0.590 & 0.9952 & 1.687 \\
\hline 5.67 & 0.703 & 0.9961 & 1.417 \\
\hline 5.94 & 0.740 & 0.9965 & 1.347 \\
\hline 6.81 & 0.853 & 0.9969 & 1.169 \\
\hline 7.16 & 0.897 & 0.9973 & 1.112 \\
\hline \multicolumn{4}{|l|}{$T=318.55 \mathrm{~K}$} \\
\hline 3.06 & 0.360 & 0.9941 & 2.761 \\
\hline 3.74 & 0.445 & 0.9951 & 2.236 \\
\hline 4.05 & 0.475 & 0.9953 & 2.095 \\
\hline 4.30 & 0.500 & 0.9955 & 1.991 \\
\hline 5.05 & 0.585 & 0.9958 & 1.702 \\
\hline 5.83 & 0.675 & 0.9967 & 1.477 \\
\hline 6.21 & 0.728 & 0.9949 & 1.367 \\
\hline 6.93 & 0.795 & 0.9943 & 1.251 \\
\hline 7.14 & 0.810 & 0.9937 & 1.227 \\
\hline 7.80 & 0.899 & 0.9929 & 1.104 \\
\hline
\end{tabular}

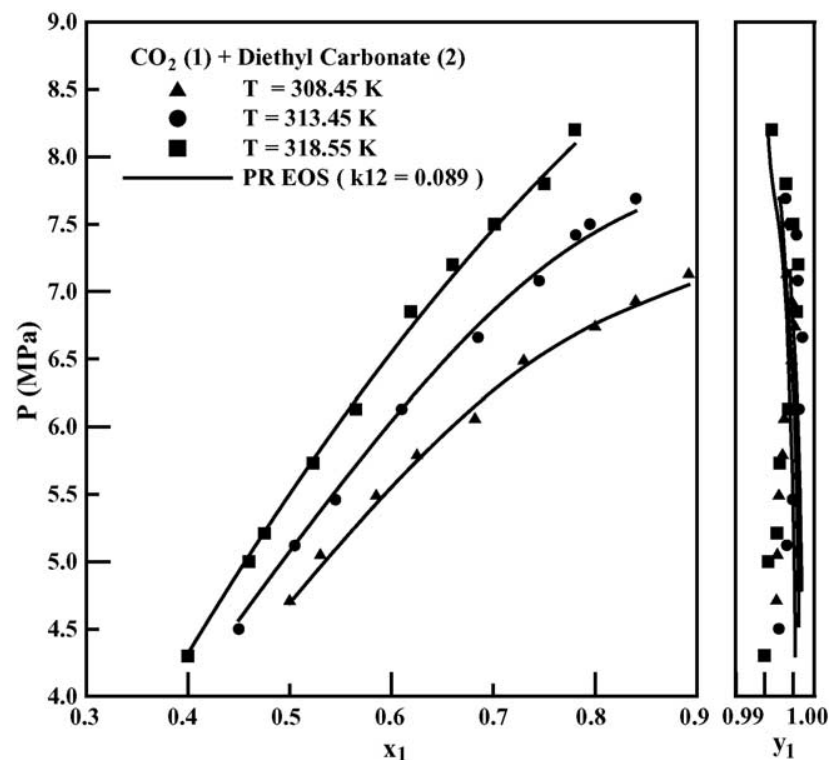

Fig. 4. VLE results of the binary mixture of $\mathrm{CO}_{2}(1)+$ diethyl carbonate (2).
Table 3

Experimental VLE results for the binary mixture of $\mathrm{CO}_{2}(1)+$ diethyl carbonate (2)

\begin{tabular}{|c|c|c|c|}
\hline \multirow[t]{2}{*}{ Pressure (MPa) } & \multicolumn{2}{|c|}{ Equilibrium composition } & \multirow{2}{*}{$\begin{array}{l}\text { Equilibrium } \\
\text { constant, } K_{1}\end{array}$} \\
\hline & $x_{1}$ & $y_{1}$ & \\
\hline \multicolumn{4}{|l|}{$T=308.45 \mathrm{~K}$} \\
\hline 4.72 & 0.500 & 0.9947 & 1.989 \\
\hline 5.06 & 0.530 & 0.9948 & 1.877 \\
\hline 5.50 & 0.585 & 0.9950 & 1.701 \\
\hline 5.80 & 0.625 & 0.9955 & 1.593 \\
\hline 6.07 & 0.682 & 0.9958 & 1.460 \\
\hline 6.50 & 0.730 & 0.9968 & 1.365 \\
\hline 6.75 & 0.800 & 0.9973 & 1.247 \\
\hline 6.94 & 0.840 & 0.9968 & 1.187 \\
\hline 7.14 & 0.892 & 0.9961 & 1.117 \\
\hline \multicolumn{4}{|l|}{$T=313.45 \mathrm{~K}$} \\
\hline 4.50 & 0.450 & 0.9950 & 2.211 \\
\hline 5.12 & 0.505 & 0.9961 & 1.972 \\
\hline 5.46 & 0.545 & 0.9969 & 1.829 \\
\hline 6.13 & 0.610 & 0.9978 & 1.636 \\
\hline 6.66 & 0.685 & 0.9983 & 1.457 \\
\hline 7.08 & 0.745 & 0.9977 & 1.339 \\
\hline 7.42 & 0.781 & 0.9975 & 1.277 \\
\hline 7.50 & 0.795 & 0.9965 & 1.253 \\
\hline 7.69 & 0.840 & 0.9960 & 1.186 \\
\hline \multicolumn{4}{|l|}{$T=318.55 \mathrm{~K}$} \\
\hline 4.30 & 0.400 & 0.9933 & 2.483 \\
\hline 5.00 & 0.460 & 0.9935 & 2.160 \\
\hline 5.21 & 0.475 & 0.9947 & 2.094 \\
\hline 5.73 & 0.523 & 0.9951 & 1.903 \\
\hline 6.13 & 0.565 & 0.9963 & 1.763 \\
\hline 6.85 & 0.619 & 0.9975 & 1.611 \\
\hline 7.20 & 0.660 & 0.9977 & 1.512 \\
\hline 7.50 & 0.701 & 0.9970 & 1.422 \\
\hline 7.80 & 0.750 & 0.9960 & 1.328 \\
\hline 8.20 & 0.780 & 0.9940 & 1.274 \\
\hline
\end{tabular}

The VLE data measured in this study were correlated by the most commonly used equation of state method. The Peng-Robinson EOS [12]:

$$
\begin{aligned}
& p=\frac{R T}{v-b}-\frac{a}{v(v+b)+b(v-b)} \\
& a=0.45724 \frac{R^{2} T_{\mathrm{c}}^{2}}{P_{\mathrm{c}}} \alpha(T) \\
& b=0.07780 \frac{R T_{\mathrm{c}}}{P_{\mathrm{c}}} \\
& \alpha(T)=\left[1+\left(0.37464+1.54226 \omega-0.26992 \omega^{2}\right)\right. \\
& \left.\times\left(1-\sqrt{\frac{T}{T_{\mathrm{c}}}}\right)\right]^{2}
\end{aligned}
$$

and the Soave-Redlich-Kwong EOS [13]:

$$
P=\frac{R T}{v-b}-\frac{a}{v(v+b)}
$$


Table 4

Experimental VLE results for the binary mixture of $\mathrm{CO}_{2}(1)+$ ethyl butyrate (2)

\begin{tabular}{|c|c|c|c|}
\hline \multirow[t]{2}{*}{ Pressure (MPa) } & \multicolumn{2}{|c|}{ Equilibrium composition } & \multirow{2}{*}{$\begin{array}{l}\text { Equilibrium } \\
\text { constant, } K_{1}\end{array}$} \\
\hline & $x_{1}$ & $y_{1}$ & \\
\hline \multicolumn{4}{|l|}{$T=308.45 \mathrm{~K}$} \\
\hline 4.80 & 0.480 & 0.9947 & 2.072 \\
\hline 5.30 & 0.530 & 0.9958 & 1.879 \\
\hline 5.65 & 0.580 & 0.9966 & 1.718 \\
\hline 6.00 & 0.630 & 0.9974 & 1.583 \\
\hline 6.30 & 0.670 & 0.9968 & 1.488 \\
\hline 6.60 & 0.725 & 0.9953 & 1.373 \\
\hline 6.80 & 0.810 & 0.9940 & 1.227 \\
\hline \multicolumn{4}{|l|}{$T=313.45 \mathrm{~K}$} \\
\hline 4.60 & 0.430 & 0.9957 & 2.316 \\
\hline 5.10 & 0.480 & 0.9961 & 2.075 \\
\hline 5.70 & 0.535 & 0.9969 & 1.863 \\
\hline 6.20 & 0.595 & 0.9978 & 1.677 \\
\hline 6.70 & 0.650 & 0.9983 & 1.536 \\
\hline 7.05 & 0.690 & 0.9977 & 1.446 \\
\hline 7.40 & 0.755 & 0.9965 & 1.320 \\
\hline 7.90 & 0.820 & 0.9950 & 1.213 \\
\hline \multicolumn{4}{|l|}{$T=318.55 \mathrm{~K}$} \\
\hline 4.55 & 0.395 & 0.9960 & 2.522 \\
\hline 4.90 & 0.430 & 0.9965 & 2.317 \\
\hline 5.40 & 0.470 & 0.9969 & 2.121 \\
\hline 6.00 & 0.530 & 0.9971 & 1.881 \\
\hline 6.60 & 0.580 & 0.9973 & 1.719 \\
\hline 7.20 & 0.640 & 0.9985 & 1.560 \\
\hline 8.10 & 0.760 & 0.9960 & 1.311 \\
\hline 8.90 & 0.860 & 0.9940 & 1.156 \\
\hline
\end{tabular}

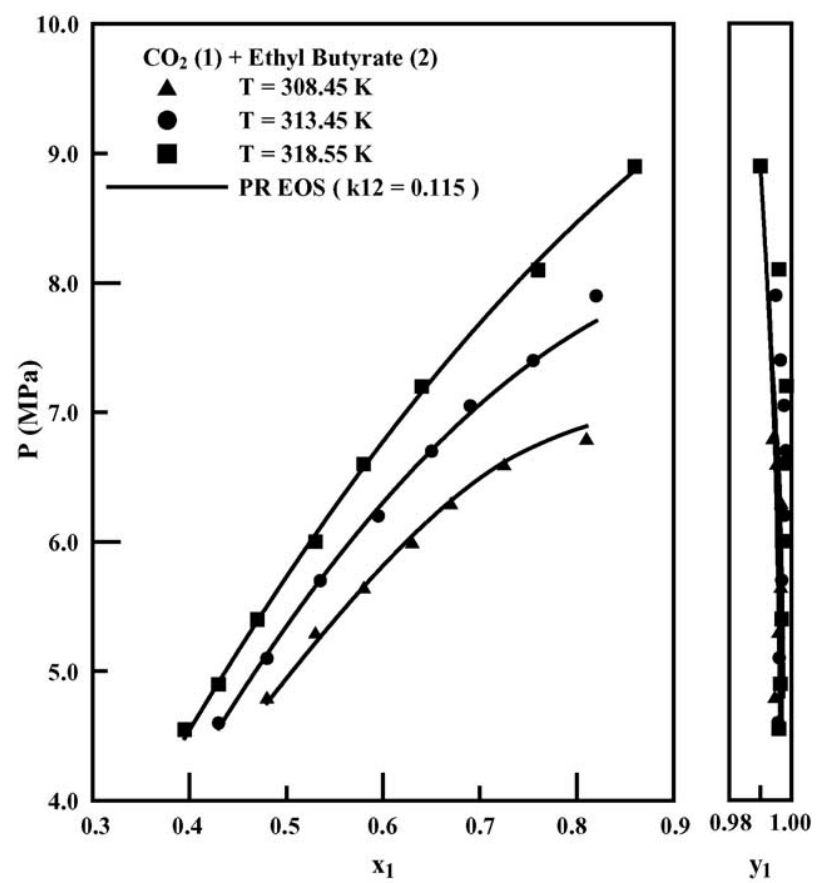

Fig. 5. VLE results of the binary mixture of $\mathrm{CO}_{2}$ (1) + ethyl butyrate (2).
Table 5

Pure component properties used in this work [18]

\begin{tabular}{lllll}
\hline Component & $T_{\mathrm{c}}(\mathrm{K})$ & $P_{\mathrm{c}}(\mathrm{MPa})$ & $v_{\mathrm{c}}\left(\mathrm{m}^{3} \mathrm{kmol}^{-1}\right)$ & $\omega$ \\
\hline Carbon dioxide & 304.19 & 7.38 & 0.094 & 0.228 \\
Ethanol & 516.25 & 6.38 & 0.167 & 0.637 \\
Isopropyl acetate & 538.00 & 3.58 & 0.336 & 0.355 \\
Diethyl carbonate & 576.00 & 3.39 & 0.356 & 0.485 \\
Ethyl butyrate & 566.00 & 3.06 & 0.421 & 0.463 \\
\hline
\end{tabular}

$a=0.42748 \frac{R^{2} T_{\mathrm{c}}^{2}}{P_{\mathrm{c}}} \alpha(T)$

$b=0.08664 \frac{R T_{\mathrm{c}}}{P_{\mathrm{c}}}$

$\alpha(T)=\left[1+\left(0.48+1.574 \omega-0.176 \omega^{2}\right)\left(1-\sqrt{\frac{T}{T_{\mathrm{c}}}}\right)\right]^{2}$

were employed in these calculations. The EOS parameters were determined from the critical constants of pure fluids that are listed in Table 5. Various mixing rules were used to evaluate the EOS parameters for fluid mixtures. For the traditional van der Waals one-fluid (VDW1) mixing rule, we have:

$a_{\mathrm{m}}=\sum \sum x_{i} x_{j}\left(a_{i} a_{j}\right)^{0.5}\left(1-k_{i j}\right)$

$b_{\mathrm{m}}=\sum x_{i} b_{i}$

where $k_{i j}$ is the binary interaction parameter. If one additional binary interaction parameter is used for $b_{\mathrm{m}}$, we have the VDW2 mixing rule:

$b_{\mathrm{m}}=\sum \sum x_{i} x_{j} \frac{b_{i}+b_{j}}{2}\left(1-l_{i j}\right)$

The optimally fitted temperature-independent binary interaction parameters were determined through bubble point calculations by minimizing the absolute average deviation (AAD) in calculated equilibrium pressure and compositions.

The other Panagiotoupoulos-Reid (PR) mixing rules [14] give a composition dependent model. In the PR mixing model, the EOS energy parameter is:

$a_{\mathrm{m}}=\sum \sum x_{i} x_{j}\left(a_{i} a_{j}\right)^{0.5}\left[1-k_{i j}+\left(k_{i j}-k_{j i}\right) x_{i}\right]$

and the volume parameter is given by Eq. (11). Although the PR mixing model has limit for the extension to multicomponent mixtures, it is applicable in correlating binary VLE data.

Besides the van der Waals type mixing models, a groupcontribution mixing model proposed by Huron and Vidal [15] was also used in this study. Applying this model, the excess Gibbs energy calculated from an EOS at an infinite pressure reference state was set equal to that calculated from the UNIQUAC [16] activity coefficient model. Two binary parameters of the UNIQUAC model were determined by regressing the 
Table 6

Correlated results of experimental VLE data of three binary mixtures using various EOS and mixing rules

\begin{tabular}{|c|c|c|c|c|c|c|c|c|c|c|}
\hline \multirow[t]{2}{*}{ Mixing rule } & \multicolumn{5}{|c|}{ Peng-Robinson EOS } & \multicolumn{5}{|c|}{ Soave-Redlich-Kwong EOS } \\
\hline & $k_{12}$ & $l_{12}\left(\right.$ or $\left.k_{21}\right)$ & AADP (\%) & $10^{2} \Delta y_{1}$ & $\operatorname{AADK}_{1}(\%)$ & $k_{12}$ & $l_{12}\left(\right.$ or $\left.k_{21}\right)$ & $\operatorname{AADP}(\%)$ & $10^{2} \Delta y_{1}$ & $\mathrm{AADK}_{1}(\%)$ \\
\hline \multicolumn{11}{|c|}{$\mathrm{CO}_{2}(1)+$ isopropyl acetate $(2)$} \\
\hline VDW1 & 0.047 & & 1.15 & 0.41 & 0.71 & 0.048 & & 1.25 & 0.34 & 0.77 \\
\hline VDW2 & 0.043 & -0.010 & 1.07 & 0.43 & 0.69 & 0.043 & -0.012 & 1.13 & 0.37 & 0.71 \\
\hline Panagiotopoulos-Reid & 0.060 & 0.047 & 1.07 & 0.43 & 0.68 & 0.064 & 0.475 & 1.14 & 0.36 & 0.74 \\
\hline \multicolumn{11}{|c|}{$\mathrm{CO}_{2}(1)+$ diethyl carbonate $(2)$} \\
\hline VDW1 & 0.089 & & 0.91 & 0.17 & 0.50 & 0.091 & & 0.84 & 0.17 & 0.50 \\
\hline VDW2 & 0.093 & 0.007 & 0.79 & 0.17 & 0.49 & 0.094 & 0.005 & 0.78 & 0.17 & 0.50 \\
\hline Panagiotopoulos-Reid & 0.078 & 0.090 & 0.79 & 0.18 & 0.45 & 0.083 & 0.092 & 0.78 & 0.17 & 0.44 \\
\hline \multicolumn{11}{|l|}{$\mathrm{CO}_{2}(1)+$ ethyl butyrate (2) } \\
\hline VDW1 & 0.115 & & 0.65 & 0.75 & 0.41 & 0.121 & & 0.68 & 0.73 & 0.45 \\
\hline VDW2 & 0.114 & -0.003 & 0.62 & 0.75 & 0.57 & 0.119 & -0.003 & 0.66 & 0.73 & 0.44 \\
\hline Panagiotopoulos-Reid & 0.119 & 0.114 & 0.62 & 0.75 & 0.42 & 0.126 & 0.120 & 0.66 & 0.73 & 0.51 \\
\hline
\end{tabular}

$\operatorname{AADP}(\%)=\frac{100}{n} \sum_{k=1}^{n} \frac{\left|P^{\exp }-P^{\text {cal }}\right|_{k}}{P_{k}^{\exp }}, \Delta y_{1}=\frac{1}{n} \sum_{k=1}^{n}\left|y_{1}^{\mathrm{cal}}-y_{1}^{\exp }\right|_{k}$ and $\operatorname{AADK}_{1}(\%)=\frac{100}{n} \sum_{k=1}^{n}\left|\frac{K_{1}^{\text {cal }}-K_{1}^{\text {exp }}}{K_{1}^{\exp }}\right|_{k}$. The summation is over all data points $k$.

experimental VLE data through the minimization of the following objective function:

$\operatorname{obj}=\sum\left|\frac{P^{\exp }-P^{\text {cal }}}{P^{\exp }}\right|+\sum\left|y_{1}^{\exp }-y_{1}^{\mathrm{cal}}\right|$

The optimally fitted binary interaction parameters from either the PR or SRK EOS using various mixing rules are listed in Table 6 . These binary interaction parameters were empirically obtained and no relationship with respect to the physical properties of solutes was attempted. It is shown that the experimental VLE data and $K_{1}$ values are satisfactorily correlated by either EOS and mixing rules with optimal binary interaction parameters. The VDW1 mixing rules are the simplest with only one temperature-independent binary interaction parameter. The calculated results with the VDW1 mixing rules are also shown in Figs. 3-5. Table 7 shows the best-fitted binary parameters of the UNIQUAC model and the correlation results for three binary systems. It is again demonstrated that satisfactory calcula-

Table 7

Correlated results of the experimental VLE data of three binary mixtures by the Huron-Vidal mixing rule with the UNIQUAC activity coefficient model

\begin{tabular}{|c|c|c|c|c|}
\hline EOS & $A_{12}\left(\mathrm{~kJ} \mathrm{~mol}^{-1}\right)$ & $A_{21}\left(\mathrm{~kJ} \mathrm{~mol}^{-1}\right)$ & $\operatorname{AADP}(\%)$ & $10^{2} \Delta y_{1}$ \\
\hline \multicolumn{5}{|c|}{$\mathrm{CO}_{2}(1)+$ isopropyl acetate (2) } \\
\hline PR & 0.581 & 1.148 & 1.010 & 0.423 \\
\hline SRK & 0.406 & 1.262 & 1.068 & 0.358 \\
\hline \multicolumn{5}{|c|}{$\mathrm{CO}_{2}(1)+$ diethyl carbonate (2) } \\
\hline PR & 1.858 & 0.636 & 0.837 & 0.175 \\
\hline SRK & 1.743 & 0.641 & 0.820 & 0.171 \\
\hline \multicolumn{5}{|c|}{$\mathrm{CO}_{2}(1)+$ ethyl butyrate (2) } \\
\hline PR & 1.887 & 1.273 & 0.751 & 0.749 \\
\hline SRK & 1.809 & 1.250 & 0.702 & 0.728 \\
\hline
\end{tabular}

$\operatorname{AADP}(\%)=\frac{100}{n} \sum_{k=1}^{n} \frac{\left|P^{\text {exp }}-P^{\text {cal }}\right| k}{P_{k}^{\exp }}$ and $\Delta y_{1}=\frac{1}{n} \sum_{k=1}^{n}\left|y_{1}^{\text {cal }}-y_{1}^{\exp }\right|_{k}$. The summation is over all data points $k$. Parameter $A_{i j}=u_{i j}-u_{j j}$, where $u_{i j}$ is the energy of interaction between molecules $i$ and $j$. The UNIQUAC equations were taken from Ref. [16]. tion results for bubble point pressure and composition are obtained.

\section{Conclusion}

VLE measurements for carbon dioxide with isopropyl acetate, diethyl carbonate and ethyl butyrate are presented at $308.45,313.45$ and $318.55 \mathrm{~K}$ and pressure up to 8.9 MPa. The VLE data are correlated using the cubic type Peng-Robinson or Soave-Redlich-Kwong equations of state with various mixing rules. The optimally fitted binary parameters are reported and the correlation results are satisfactorily observed.

\section{List of symbols}

$a, b \quad$ equation of state parameters

$k, l \quad$ binary interaction parameters

$P \quad$ pressure

$R \quad$ gas constant

$T \quad$ temperature

$v \quad$ molar volume

$x \quad$ mole fraction in the liquid phase

$y \quad$ mole fraction in the vapor phase

\section{Greek letter}

$\omega \quad$ acentric factor

\section{Subscripts}

c critical property

$i, j \quad$ component $i$ or $j$

$\mathrm{m} \quad$ mixture property

\section{Acknowledgement}

The authors are grateful to the National Science Council, ROC, for supporting this research. 


\section{References}

[1] R.E. Fornari, P. Alessi, I. Kikic, Fluid Phase Equilib. 57 (1990) 1-33.

[2] R. Dohrn, G. Brunner, Fluid Phase Equilib. 106 (1995) 213-282.

[3] M. Christov, R. Dohrn, Fluid Phase Equilib. 202 (2002) 153-218.

[4] K.W. Cheng, S.J. Kuo, M. Tang, Y.P. Chen, J. Supercrit. Fluids 18 (2000) 87-99.

[5] K.W. Cheng, M. Tang, Y.P. Chen, Fluid Phase Equilib. 181 (2001) $1-16$.

[6] L.C. Feng, K.W. Cheng, M. Tang, Y.P. Chen, J. Supercrit. Fluids 21 (2001) 111-121.

[7] J.H. Yoon, H.S. Lee, H. Lee, J. Chem. Eng. Data 38 (1993) 5355.

[8] T. Laursen, P. Rasmussen, S.I. Andersen, J. Chem. Eng. Data 47 (2002) 198-202.

[9] K. Suzuki, H. Sue, M. Itou, R.L. Smith, H. Inomata, K. Arai, S. Sato, J. Chem. Eng. Data 35 (1990) 63-66.
[10] J.H. Yoon, H.S. Lee, B.H. Chung, Fluid Phase Equilib. 102 (1994) 287-292.

[11] http://webbook.nist.gov/chemistry.

[12] D.Y. Peng, D.B. Robinson, Ind. Eng. Chem. Fundam. 15 (1976) 59-64.

[13] G. Soave, Chem. Eng. Sci. 27 (1972) 1197-1203.

[14] A.Z. Panagiotoupoulos, R.C. Reid, ACS Symp. Ser. 300 (1986) $571-582$.

[15] M.J. Huron, J. Vidal, Fluid Phase Equilib. 3 (1979) 255-271.

[16] D.S. Abrams, J.M. Prausnitz, AIChE J. 21 (1975) 116-128.

[17] D.R. Lide, H.P.R. Frederikse, CRC Handbook of Chemistry and Physics, 80th ed., CRC Press Inc., Boca Raton, FL, 1999.

[18] T.E. Daubert, R.P. Danner, Physical and Thermodynamic Properties of Pure Chemicals: Data Compilation, Hemisphere, New York, 1989.

[19] J.A. Riddick, W.B. Bunger, T.K. Sakano, Organic Solvents: Physical Properties and Methods of Purification, fourth ed., John Wiley \& Sons, New York, 1986. 